\title{
Clinical factors in prediction of prognosis after anterior resection with total mesorectal excision for carcinoma of the rectum
}

\author{
BARTLOMIEJ SZYNGLAREWICZ ${ }^{1}$, RAFAL MATKOWSKI ${ }^{1,2}$, JOZEF FORGACZ ${ }^{1}$, \\ MAREK PUDELKO ${ }^{1}$, ZBIGNIEW SMORAG $^{1}$, JACEK DRYL ${ }^{2}$ and JAN KORNAFEL ${ }^{2}$ \\ ${ }^{1}$ Second Department of Surgical Oncology, Lower Silesian Oncology Center; \\ ${ }^{2}$ Department of Oncology, Wroclaw Medical University, Wroclaw, Poland
}

Received August 28, 2006; Accepted October 2, 2006

\begin{abstract}
The aim of the study was to estimate the long-term results and the prognostic value of clinical and pathological factors following R0 anterior resection with total mesorectal excision (TME). Ninety-eight consecutive patients with histologically confirmed rectal cancer were studied prospectively with five-year follow-up. Survival was calculated using the Kaplan-Meier method and differences between curves were tested by the log-rank test. Multivariate analysis was performed using the Cox regression model. Recurrence-free survival (RFS) was $63.6 \%$. Mean time of recurrence was 13.8 months (range 3-38). Local recurrence rate was $7.8 \%$ with the mean time of 12.7 months (range 3-25). In univariate analysis Dukes' stage (RFS for stage: $\mathrm{A}=93.2 \%$; $\mathrm{B}=53.8 \%$; $\mathrm{C}=26.3 \%$ ) and preoperative CEA serum level (s-CEA) (for $\mathrm{s}-\mathrm{CEA} \leq 5 \mathrm{ng} / \mathrm{ml} \mathrm{RFS}=93.8 \%$; for $\mathrm{s}-\mathrm{CEA}>5 \mathrm{ng} / \mathrm{ml} \mathrm{RFS}=$ $5.9 \%)$ significantly influenced survival $(\mathrm{P}<0.005$ and $\mathrm{P}<0.00001)$. These parameters were also found to be independent prognostic factors in multivariate analysis $(\mathrm{P}<0.05$ and $\mathrm{P}<0.00001)$. Survival was worse in older female patients with low-localised poorly differentiated tumors; however, those variables had not significant impact on prognosis. Neither symptom duration nor mucinous histology was significantly related to survival. Using TME technique a low local recurrence rate resulting in improved survival can be achieved. Apart from clinicopathological staging, elevated s-CEA can identify patients with poor prognosis. In addition to TME adjuvant therapy for this high-risk group should be considered.
\end{abstract}

\section{Introduction}

Cancer of the colon and rectum remains a problem of public health. It is assessed that in the world there are $\sim 1$ million new cases and 500,000 cancer-related deaths each year (1).

Correspondence to: Dr B. Szynglarewicz, Lower Silesian Oncology Center, Plac Hirszfelda 12, 53-413 Wroclaw, Poland E-mail: szynglarewicz.b@dco.com.pl

Key words: rectal cancer, anterior resection, total mesorectal excision, prognostic factors, carcinoembryonic antigen
With the development of stapling devices an anterior resection is the preferred treatment option for rectal cancer. Since the introduction of total mesorectal excision (TME) by Heald et al an improved local control and post-operative survival can be achieved (2). Despite advances in surgical technique, numerous patients have a high risk of local or distant cancer recurrence and may benefit from adjuvant therapy $(3,4)$. For 70 years the Dukes' classification has remained the most often used clinical parameter for the identification of cancer recurrence risk. On the other hand, the prognoses of patients being at the same stage of this system can differ considerably, thus more accurate and sensitive prognostic factors are needed. Many clinical and pathological features, patient- and tumor-related variables are still investigated (5-8). Recent studies of predictive significance of genetic alterations and molecular factors have provided very promising results (8-14). Their real prognostic value needs further evaluation in controlled randomised trials. However, some authors claim that their usefulness for regular clinical application is disputable (15).

\section{Materials and methods}

Patients. From January 1998 to December 1999 at the Second Department of Surgical Oncology at Lower Silesian Oncology Center 98 consecutive patients with histologically confirmed rectal cancer underwent an anterior resection with sphincter preservation. Seventy-seven of these $(75 \%)$ entered the study fulfilling the inclusion criteria: primary tumor localised maximally $12 \mathrm{~cm}$ from the anal verge, absence of distant metastases (intraoperative examination, chest radiogram, abdominal sonography, CT scanning), lack of intraoperative bowel perforation, absence of macroscopic infiltration of adjacent organs, distal and radial margins microscopically free of cancer infiltration (R0 resection) and lack of liver disorders. All patients underwent elective surgery with preoperative bowel preparation by means of 41 of polyethylene glycol solution one day before surgery. Prophylactic antibiotics were administered at the anaesthesia induction. Time of the follow-up was five years. The data were prospectively collected.

Surgical treatment. Resection of the rectum was performed according to the TME principles with sharp dissection under 
Table I. Impact of clinical and pathological variables on five-year recurrence-free survival.

\begin{tabular}{|c|c|c|c|c|}
\hline Patient characteristics & $\begin{array}{l}\text { Number }(\%) \\
\text { of patients }\end{array}$ & $\begin{array}{c}\text { Recurrence-free } \\
\text { survival rate }\end{array}$ & $\begin{array}{l}\text { Univariate } \\
\text { analysis }\end{array}$ & $\begin{array}{c}\text { Multivariate } \\
\text { analysis }\end{array}$ \\
\hline Age $<60$ years & $33(43 \%)$ & $71.7 \pm 8.0$ & & \\
\hline Age $\geq 60$ years & $44(57 \%)$ & $56.7 \pm 7.5$ & $\mathrm{P}=0.209$ & NS \\
\hline Men & $43(56 \%)$ & $64.5 \pm 7.4$ & & \\
\hline Women & $34(44 \%)$ & $61.0 \pm 8.5$ & $\mathrm{P}=0.685$ & NS \\
\hline Tumor $>7 \mathrm{~cm}$ from anal verge & $19(25 \%)$ & $72.7 \pm 10.4$ & & \\
\hline Tumor $\leq 7 \mathrm{~cm}$ from anal verge & $58(75 \%)$ & $60.0 \pm 6.5$ & $\mathrm{P}=0.249$ & NS \\
\hline Symptom duration $<3$ months & $15(20 \%)$ & $66.7 \pm 12.2$ & & \\
\hline Symptom duration 3-6 months & $17(22 \%)$ & $69.3 \pm 11.5$ & & \\
\hline Symptom duration 6-12 months & $30(38 \%)$ & $56.7 \pm 9.0$ & $\mathrm{P}=0.484$ & NS \\
\hline Symptom duration $>12$ months & $15(20 \%)$ & $65.0 \pm 12.7$ & & \\
\hline Preoperative s-CEA $\leq 5 \mathrm{ng} / \mathrm{ml}$ & $48(62 \%)$ & $93.8 \pm 3.5$ & & \\
\hline Preoperative s-CEA $>5 \mathrm{ng} / \mathrm{ml}$ & $29(38 \%)$ & $5.9 \pm 5.3$ & $\mathrm{P}<0.00001$ & $\mathrm{P}<0.00001$ \\
\hline Dukes' stage A & $32(41 \%)$ & $93.2 \pm 4.6$ & & \\
\hline Dukes' stage B & $26(34 \%)$ & $53.8 \pm 9.8$ & $\mathrm{P}<0.005$ & $\mathrm{P}<0.05$ \\
\hline Dukes' stage C & $19(25 \%)$ & $26.3 \pm 10.1$ & $\mathrm{P}<0.0001$ & $\mathrm{P}<0.05$ \\
\hline Malignancy grade G1 & $10(15 \%)$ & $78.8 \pm 13.4$ & & \\
\hline Malignancy grade G2 & $31(46 \%)$ & $63.7 \pm 8.7$ & $\mathrm{P}=0.391$ & NS \\
\hline Malignancy grade G3 & $26(39 \%)$ & $57.7 \pm 9.7$ & & \\
\hline Non-mucinous histology & $67(87 \%)$ & $63.5 \pm 6.0$ & & \\
\hline Mucinous histology & $10(13 \%)$ & $60.0 \pm 15.5$ & $\mathrm{P}=0.843$ & NS \\
\hline
\end{tabular}

s-CEA, preoperative serum level of carcinoembryonic antigen; NS, not significant.

direct vision of the plane between the parietal and visceral pelvic fascia to the levator level. Special effort was made to identify and preserve the hypogastric plexuses and pelvic nerves. Distal margin of minimum $2 \mathrm{~cm}$ was achieved. End to end anastomosis was constructed using double-stapling technique with the Proximate TLH transverse and Proximate ILS circular intraluminal devices (Ethicon Endo-Surgery Europe, Norderstedt, Germany). Bowel lavage was performed using $2 \%$ povidone iodine solution.

Adjuvant therapy. Adjuvant therapy was achieved for patients with tumors penetrating beyond the bowel wall (Dukes' B, $\mathrm{n}=26$ ) or with lymph node metastases (Dukes' C, $\mathrm{n}=19$ ). Staging was established by means of preoperative endorectal ultrasound and confirmed by histological examination of resected specimen. Twenty-eight patients received preoperative five-day radiation 25 Gy (5x5 Gy) and postoperative chemotherapy with 5-fluorouracil and folinic acid. Seventeen patients received adjuvant radiochemotherapy (5-fluorouracil + folinic acid and 50.4 Gy radiation: 25x1.8 Gy $+5.4 \mathrm{~Gy}$ boost).

Follow-up. Follow-up was scheduled every three months during the first postoperative year and every six months thereafter. Physical examination, blood tests, serum markers, barium enema, endoscopy, chest radiograph and abdominal ultrasound were performed. In each case where cancer recurrence was suspected more precise investigation using endorectal sonography, computed tomography or radioisotope scanning was performed.

Clinical factors. For each patient gender and age were recorded. Age ranged from 35 to 89 years, mean was 60.7 , median was 60 . Thus, we stated a level of 60 years as a cut-off point for age analysis. The site of the primary tumor was divided in two groups: $>7 \mathrm{~cm}$ and $\leq 7 \mathrm{~cm}$ from the anal verge for separate consideration of the intra- and extraperitoneal tumors. Symptom duration (divided into: $\leq 3$ months, 3-6, 6-12, >12 months) was obtained from the patients records. Patients were also classified according to preoperative serum level of carcinoembryonic antigen (s-CEA) with the cut-off value of $5 \mathrm{ng} / \mathrm{ml}$ (16). Detailed characteristics of patient subgroups are given in Table I.

Pathological factors. Staging of tumours was evaluated according to Dukes' criteria. Patients with tumors without mucin secretion were divided into three groups depending on differentiation grade: well-differentiated (G1), moderately (G2) and poorly differentiated (G3). Adenocarcinomas with mucin histology were distinctly evaluated from non-mucinous ones (Table I). 
Statistical analysis. Data analysis was performed using the software Statistica $^{\mathrm{TM}}$ version 5. All clinical and pathological variables were considered in univariate analysis. To examine the impact of individual parameters on long-term outcome, five-year survival analysis was used. Recurrence-free survival (RFS) was calculated according to the Kaplan-Meier method and differences between curves were tested by the log-rank test, using $\mathrm{P}<0.05$ as the significance limit. Factors significant in univariate analysis were entered into the Cox proportional hazards regression model for multivariate analysis. Using this approach we obtained independent factors on prognosis.

\section{Results}

There were no postoperative deaths. Forty-nine patients were still alive without any evidence of recurrent disease after five years of follow-up in each case. Thus, the five-year RFS rate was $63.6 \%$ (Kaplan-Meier estimation: $63.0 \pm 5.6 \%$ ). Four patients were alive with systemic dissemination, 24 patients died before the end of follow-up. Mean time of recurrence was 13.8 months (range, 3-38 months). In 6 patients (7.8\%) local recurrence developed with the mean time of 12.7 months (range, 3-25 months).

Survival was worse in older ( $\geq 60$ years) and female patients. In the univariate analysis influence of patient age and sex on prognosis was not significant. Survival following curative resection of cancers localised $>7 \mathrm{~cm}$ from the anal verge was better than those with lower sites, but site of the primary tumor did not appear to be significantly important in the prediction of outcome. Shorter periods ( $<3$ and 3-6 months) between first symptoms of disease and treatment were related to a better survival, although not significantly different in comparison with symptom duration lasting 6-12 and $>12$ months. An increased $(>5 \mathrm{ng} / \mathrm{ml})$ preoperative sCEA was of importance in the prediction of poorer prognosis with a very high degree of significance $(\mathrm{P}<0.00001$, relative risk $r r=13.79,95 \% \mathrm{CI}=4.57-41.66)$. Differences in survival rates according to Dukes' stage also led to a high degree of statistical significance $(\mathrm{P}<0.00001$; Dukes' $\mathrm{B}: \mathrm{P}=0.00363$, $\mathrm{rr}=9.23,95 \% \mathrm{CI}=1.81-30.09$; Dukes' C: $\mathrm{P}=0.00008, \mathrm{rr}=20.1$, 95\% CI=3.00-46.33). Better outcome was observed in patients with well or moderate differentiation of cancer but without statistical significance compared with poorly differentiated tumors. Carcinomas with mucinous histology did not show any significant effect on patient survival.

The Cox proportional hazards regression analysis identified preoperative s-CEA as the most important prognostic factor $(\mathrm{P}<0.00001, \mathrm{rr}=27.90)$. Significant impact of Dukes' stage on five-year RFS also persisted in the multivariate analysis $(\mathrm{P}<0.005$; Dukes' $\mathrm{B}$ : $\mathrm{P}=0.0172, \mathrm{rr}=6.33$; Dukes' C: $\mathrm{P}=0.0260, \mathrm{rr}=5.63$ ) but was less important than preoperative s-CEA. The results are summarized in Table I.

\section{Discussion}

The RFS rate achieved in our patients was high. The main reason seems to be that $>40 \%$ of patients were in the early stage of disease (Dukes' A). It may be also partially explained by accurate preoperative staging and adequate pathological examination of resected specimen; therefore, the exclusion of patients with systemic dissemination or persisted tumor deposits from the study.

In rectal carcinoma an effective prediction of patient outcome is a clinical problem. The significant impact of tumor stage on survival following R0 resection is nondisputable. Many other parameters are extensively investigated but results are more discordant and conflicting. We noted better outcomes for younger and male patients with well or moderately differentiated tumors sited at the middle-upper rectum. However, the differences were not significant, possibly due to the small sample size. Cerrotini et al reviewed 801 patients after curative resection and found the worse 10 -year overall survival for the youngest ( $<50$ years) and elderly $(>70)$, poorly differentiated cancers and mucinous tumors (7). In our study, apart from the Dukes' stage, only preoperative s-CEA significantly affected RFS survival in uniand multivariate analysis.

CEA is a surface-bound tumor-associated antigen discovered by Gold and Freedman (17). It is an intercellular adhesion glycoprotein with a molecular mass of $\sim 180 \mathrm{kDa}$, belonging to the immunoglobulin superfamily (18). CEA is expressed at low levels in the embryonic and foetal gut, adult colon epithelium and other endodermal tissues (19). Serum CEA may be elevated in smokers, patients with liver diseases and several benign and malignant disorders of the gastrointestinal tract (20). CEA is overexpressed in $\sim 95 \%$ of colorectal cancers and differs from normal expression in that it loses its typical apical localisation, is aberrantly glycosylated and actively secreted (21). The main clinical value of s-CEA in the colorectal carcinoma is the early detection of recurrence (22), but its usefulness for the prediction of long-term prognosis is investigated.

Wanebo et al first reported the relationship between elevated preoperative s-CEA ( $>5 \mathrm{ng} / \mathrm{ml})$ and higher recurrence rate (23). Similar to our study, more recent studies confirmed the significant impact of s-CEA on patient outcome in multivariate analyses $(8,24-29)$. Our group was too small for effective stratification of the s-CEA importance in Dukes' stages. Results of such stratifications made by other authors are discrepant. Harrison et al found s-CEA as a significant and independent prognostic factor for lymph node-negative cancers (30), whereas Chen et al only for stage B tumors (31). In contrast Wang et al and Bannura et al noted that higher preoperative s-CEA was related to poorer survival of lymph node-positive patients $(32,33)$. Moertel et al reported its independent prognostic value only in patients with involvement of four or more lymph nodes (34). Different results were observed in the trial of Gastrointestinal Tumor Study Group: s-CEA affected survival of patients with one to four positive nodes (35). Moreover, Wang et al in another study concluded that prediction of significant outcomes persisted for patients analysed separately at Astler-Coller stage $\mathrm{C} 1$ (lack of tumor penetration beyond the bowel wall) and C2 (presence of penetration) (36).

The cut-off point of s-CEA in our study was $5 \mathrm{ng} / \mathrm{ml}$ (the normal range in our laboratory) (16). This approach is in accordance with other investigators $(8,27-29,32,33,36)$. However, the s-CEA is a continuous variable, therefore another level as a cut-off point might be more accurate for its 
predictive value. There is agreement that increased s-CEA $(>15-17 \mathrm{ng} / \mathrm{ml})$ can significantly identify patients with the highest risk of distant metastases and the poorest survival $(29,37)$. In some studies it was more effective than Dukes' staging (37). On the other hand, Park et al reviewed 989 patients in multi-step analysis of s-CEA beginning from 1 $\mathrm{ng} / \mathrm{ml}$ and increasing by $1 \mathrm{ng} / \mathrm{ml}$ increments (normal level at $6 \mathrm{ng} / \mathrm{ml}$ ) and defined the group of patients with the best 5year disease-free survival as with s-CEA $<3 \mathrm{ng} / \mathrm{ml}$ (29). It may suggest that the cut-off point set arbitrarily at the normal s-CEA level can result in insufficient determination of its prognostic value.

Using TME technique for rectal cancer resection an optimal local control and improved survival can be achieved, also in lymph node-positive tumors (38). Due to these excellent results only limited use of adjuvant therapy is postulated by some; therefore, surgery alone as the treatment of choice is recommended (39). However, recurrent disease can develop despite TME, even in patients at the earliest stage of disease (40). These high-risk patients may be candidates for adjuvant treatment (41). For the identification of this subset other factors can be helpful. One of them is s-CEA, associated with tumor aggressiveness. In colorectal cancer CEA appears to participate in several cellular functions including intercellular and cell-matrix adhesion, signal transduction and cellular migration suggesting that CEA may have a role in disorganised growth and movement of transformed cells; thus, can facilitate tumor invasion and metastasis $(42,43)$. Therefore, s-CEA is considered a significant, independent and effective prognostic factor recommended for routine clinical application together with stage parameters (44). The real benefit from adjuvant therapy in patients with elevated $\mathrm{s}-\mathrm{CEA}$ should be stated at further controlled randomised trials. Moreover, molecular and genetic investigations are still needed for better explanation of cancer biology.

\section{References}

1. Boyle $\mathrm{P}$ and Leon ME: Epidemiology of colorectal cancer. $\mathrm{Br}$ Med Bull 64: 1-25, 2002.

2. Heald RJ, Husband EM and Ryall RDH: The mesorectum in rectal cancer surgery - the clue to the pelvic recurrence. Br J Surg 69: 613-616, 1982.

3. Minsky BD: Adjuvant therapy of resectable rectal cancer. Cancer Treat Rev 28: 181-188, 2002.

4. Glimelius BL: The role of preoperative and postoperative radiotherapy in rectal cancer. Clin Colorectal Cancer 2: 82-92, 2002.

5. Funada Y, Noguchi T, Kikuchi R, Takeno S, Uchida Y and Gabbert HE: Prognostic significance of $\mathrm{CD}^{+}$cell and macrophage peritumoral infiltration in colorectal cancer. Oncol Rep 10: 309-323, 2003.

6. Abdalla SA, Behzad F, Bsharah S, Kumar S, Amini SK, O'Dwyer ST and Habowbi NY: Prognostic relevance of microvessel density in colorectal tumours. Oncol Rep 6: 839-842, 1999.

7. Cerottini JP, Caplin S, Pampallona S and Givel JC: Prognostic factors in colorectal cancer. Oncol Rep 6: 409-414, 1999.

8. Chang S.C, Lin JK, Lin TC and Liang WY: Genetic alteration of $\mathrm{p} 53$, but not overexpression of intratumoral p53 protein, or serum p53 antibody is a prognostic factor in sporadic colorectal adenocarcinoma. Int J Oncol 26: 65-75, 2005.

9. Cunningham MP, Essapen S, Thomas H, Green M, Lovell DP, Topham C, Marks C and Modjtadehi H: Coexpression, prognostic significance and predictive value of EGFR, EGFRvIII and phosphorylated EGFR in colorectal cancer. Int J Oncol 27: 317-325, 2005 .
10. Essapen S, Thomas H, Green M, De Vries C, Cook MG, Marks C, Topham C and Modjtadehi $\mathrm{H}$ : The expression and prognostic significance of HER-2 in colorectal cancer and its relationship with clinicopathological parameters. Int J Oncol 24: 241-248, 2004.

11. Hiranuma C, Kawakami K, Oyama K, Ota N, Omura K and Watanabe G: Hypermethylation of the MYOD 1 gene is a novel prognostic factor in colorectal cancer. Int J Mol Med 13: 413-417, 2004.

12. Sogawa N, Takiguchi N, Koda K, Oda K, Satomi D, Kato K, Ishigura $\mathrm{H}$ and Miyazaki M: Value of expression of p21WAF1/ CIP1 as a prognostic factor in advanced middle and lower rectal cancer treated with preoperative radiochemotherapy. Int J Oncol 21: 787-793, 2002.

13. Aoki T, Katsumata K, Tsuchida A, Tomioka H and Kayanagi Y: Correlation between malignancy grade and p53 gene in relation to thymidine phosphorylase activity in colorectal cancer patients. Oncol Rep 9: 1267-1271, 2002.

14. Yoshikawa R, Yanagi H, Kusunoki M, Fujiwara Y, Noda M, Hashimoto-Tamaoki T and Yamamura T: Prognostic value of radiation-induced p53 in adjacent normal mucosa and p21WAF1/ CIP1 expression in rectal cancer patients. Int J Oncol 21: 1223-1228, 2002.

15. Deans GT, Parks TG, Rowlands BJ and Spence RAJ: Prognostic factors in colorectal cancer. Br J Surg 79: 608-613, 1992.

16. Hansen HJ, Snyder JJ, Miller E, van de Voorde JP, Miller ON, Hines LR and Burns JJ: Carcinoembryonic antigen (CEA) assay: a laboratory adjunct in the diagnosis and management of cancer. Hum Pathol 5: 139-147, 1974.

17. Gold P and Freedman SO: Specific carcinoembryonic antigens of the human digestive system. J Exp Med 122: 467-481, 1965.

18. Benchimol S, Fuks A, Jothy S, Beauchemin N, Shirota K and Stanners CP: Carcinoembryonic antigen, a human tumor marker, functions as an intercellular adhesion molecule. Cell 57: 327-334, 1989.

19. Thompson JA, Grunert F and Zimmermann W: Carcinoembryonic antigen gene family: molecular biology and clinical perspectives. J Clin Lab Anal 5: 344-366, 1991.

20. Bendardaf R, Lamlum H and Pyrhonen S: Prognostic and predictive molecular markers in colorectal carcinoma. Anticancer Res 24: 2519-2530, 2004.

21. Horig H, Medina FA, Conkright WA and Kaufman HL: Strategies for cancer therapy using carcinoembryonic antigen (CEA) vaccines. Exp Rev Mol Med 1462: 1-24, 2000.

22. Kattlove $H$ and Winn RJ: Ongoing care of patients after primary treatment for their cancer. CA Cancer J Clin 54: 172-196, 2003.

23. Wanebo HJ, Rao B, Pinsky CM, Hoffman RG, Stearns M, Schwartz MK and Oettgen HF: Preoperative carcinoembryonic antigen level as a prognostic indicator in colorectal cancer. $\mathrm{N}$ Engl J Med 299: 448-451, 1978.

24. Hohenberger W, Bittorf B, Papadopoulos T and Merkel S: Survival after surgical treatment of cancer of the rectum. Langenbecks Arch Surg 390: 363-372, 2005.

25. Kim JC, Lee KH, Yu CS, Kim HC, Kim JR, Chang HM, Kim JH, Kim JS and Kim TW: The clinicopathological significance of inferior mesenteric lymph node metastasis in colorectal cancer. Eur J Surg Oncol 30: 271-279, 2004.

26. Behbehani AI, Al-Sayer H, Farghaly M, Kanawati N, Mathew A, Al-Bader A and Van Dalen A: Prognostic significance of CEA and CA 19-9 in colorectal cancer in Kuwait. Int J Biol Markers 15: 51-55, 2000.

27. Turoldo A, Balani A, Scaramucci M, Pistan V, Roseano M and Liguori G: Preoperative CEA: prognostic significance in colorectal carcinoma. Tumori 89 (Suppl 4): 95-97, 2003.

28. Louhimo J, Carpelan-Holmstrom M, Alfthan H, Stenman UH, Jarvinen HJ and Haglund C: Serum HCG beta, CA 72-4 and CEA are independent prognostic factors in colorectal cancer. Int J Cancer 101: 545-548, 2002.

29. Park YJ, Park KJ, Park JG, Lee KU, Choe KJ and Kim JP: Prognostic factors in 2230 Korean colorectal cancer patients: analysis of consecutively operated cases. World J Surg 23: 721-726, 1999.

30. Harrison LE, Guillem JG, Paty P and Cohen AM: Preoperative carcinoembryonic antigen predicts outcomes in node-negative colon cancer patients: a multivariate analysis of 572 patients. J Am Coll Surg 185: 55-59, 1997. 
31. Chen CC, Yang SH, Lin JK, Lin TC, Chen WS, Jiang JK, Wang HS and Chang SC: Is it reasonable to add preoperative serum level of CEA and CA 19-9 to staging for colorectal cancer? J Surg Res 124: 169-174, 2005.

32. Wang WS, Chen PM, Chiou TJ, Liu JH, Fan FS, Lin TC, Jiang JK, Yang SH, Yen CC, Wang HS and Lin JK: Factors predictive of survival in patients with node-positive colorectal cancer in Taiwan. Hepatogastroenterology 47: 1590-1594, 2000.

33. Bannura G, Cumsille MA, Contreras J, Melo C, Barrera A, Reinero $\mathrm{M}$ and Pardo L: Prognostic factors in colorectal neoplasm. Multivariate analysis in 224 patients. Rev Med Chil 129: 237-246, 2001.

34. Moertel CG, O'Fallon JR, Go VLW, O'Connell MJ and Thynne GS: The preoperative carcinoembryonic antigen test in diagnosis, staging and prognosis of colorectal cancer. Cancer 58: 603-610, 1986

35. Steele GJr, Ellenberg S, Ramming K, O'Connell M, Moerlet C, Lessner H, Bruckner H, Horton J, Schein P, Zamcheck N, Novak J and Holyoke ED: Carcinoembryonic antigen monitoring among patients in multi-institutional adjuvant G.I. therapy protocols. Ann Surg 196: 162-169, 1982.

36. Wang WS, Lin JK, Chiou TJ, Liu JH, Fan FS, Yen CL, Lin TC, Jieng JK, Yang SH, Wang HS and Chen PM: Preoperative carcinoembryonic antigen level as an independent prognostic factor in colorectal cancer: Taiwan experience. Jpn J Clin Oncol 30: 12-16, 2000.

37. Wiratkapun S, Kraemer M, Seow-Choen F, Ho YH and Eu KW: High preoperative serum carcinoembryonic antigen predict metastatic recurrence in potentially curative colonic cancer: results of a five-year study. Dis Colon Rectum 44: 231-235, 2001.
38. Cecil TD, Sexton R, Moran BJ and Heald RJ: Total mesorectal excision results in low local recurrence rates in lymph nodepositive rectal cancer. Dis Colon Rectum 47: 1145-1150, 2004.

39. Hermanek P and Heald RJ: Pre-operative radiotherapy for rectal carcinoma? Has the case really been made for short course pre-operative radiotherapy if surgical standards for rectal carcinoma are optimal? Colorectal Dis 6: 10-14, 2004.

40. Kane JM III and Petrelli NJ: Controversies in the surgical management of rectal cancer. Semin Radiat Oncol 13: 403-418, 2003.

41. Colquhoun P, Wexner SD and Cohen A: Adjuvant therapy is valuable in the treatment of rectal cancer despite total mesorectal excision. J Surg Oncol 83: 133-139, 2003.

42. Obrink B: CEA adhesion molecules: multifunctional proteins with signal regulatory properties. Curr Opin Cell Biol 9: 616-626, 1997.

43. Von Kleist S, Miguel I, Halla B: Possible function of CEA as cell-contact inhibitory molecule. Anticancer Res 15: 1889-1894, 1995.

44. Compton CC, Fielding LP, Burgart LJ, Conley B, Cooper HS, Hamilton SR, Hammond ME, Henson DE, Hutter RV, Nagle RG, Nielsen ML, Sargent DJ, Taylor CR, Welton M and Willet C: Prognostic factors in colorectal cancer. College of American Pathologists Consensus Statement 1999. Arch Pathol Lab Med 124: 979-994, 2000. 